\title{
Estimation of Rheo-Technological Effectiveness of Polycarboxylate Superplasticizer in Filled Cement Systems in the Development of Self-compacting Concrete for High-Density Reinforced Building Constructions
}

\author{
T. Nizina ${ }^{(凶)}$, A. Balykov, V. Volodin, and D. Korovkin \\ Department of Building Structures, Ogarev Mordovia State University, \\ Saransk, Russia \\ nizinata@yandex.ru
}

\begin{abstract}
Analysis of rheo-technological effectiveness of the polycarboxylate superplasticizer Melflux $5581 \mathrm{~F}$ in the microcalcite-filled cement systems was performed. Optimal quantities of polycarboxylate superplasticizer and carbonate filler were determined, which allow obtaining highly mobile cement-mineral suspensions at reduced water content, which is an important step in the development of self-compacting concrete mixtures.
\end{abstract}

Keywords: Cement-mineral suspension $\cdot$ Rheology $\cdot$ Efficiency $\cdot$ Superplasticizer $\cdot$ Microcalcite $\cdot$ Self-compacting concrete

\section{Introduction}

Currently, there is an active growth in the area of concrete development, which the world technological community clearly classifies as cement composites of the new generation with high strength, workability, volume stability and durability (Collepardi 2006; Nawy 2001; Nizina and Balykov 2016; Nizina et al. 2017; Sivakumar et al. 2014; Tran and Kim 2017). A special place among the concretes of the new generation is occupied by Self-Compacting Concrete (SCC) - Selbstverdichtender Concrete (SVB, German), Betonautoplacant (BAP, French), which are currently fairly widespread abroad. This term, proposed in 1986 by the Japanese professor H. Okamura (Okamura and Ouchi 2003), combines concrete mixtures with high workability characteristics (standard cone flow over $55-60 \mathrm{~cm}$ at water-to-cement ratio reduced to $0.35-0.4$ or less), which are due to the high deformability of the suspension matrix, along with its high resistance to segregation or separation during movement.

A number of papers experimentally proved that one of the basic principles for producing self-compacting concrete mixtures is the presence of a significant amount of dispersed micro-particles of cement or mineral fillers (mainly 1-100 microns in size) in their formulation, which, together with Portland cement, increase the volume of a dispersion-water suspension. At the same time, not all dispersed fillers are capable of providing a higher flowability in suspension with a superplasticizer (SP) as compared 
with cement suspensions. The research (Kalashnikov et al. 2014) shows that carbonate rocks (limestone, marble, dolomite), which include particles with a significant proportion of positively charged active centers, are the most compatible with anionic superplasticizers.

Thus, the generate of self-compacting concrete mixtures must begin with the development of rheological active formulation of the filled cement binders, which allow, when mixing together with the superplasticizer, to form aggregate resistant suspensions, which have a high concentration of the solid phase, low values of the shear stress limit and plastic viscosity at high gravitational fluidity under its own weight. At the same time, the efficiency of plasticizers in such systems will depend on many factors - addition procedure and optimal quantity of the plasticizer, rheological activity of the fillers used, etc.

The purpose of the study is to determine the optimal quantity of polycarboxylate superplasticizer and carbonate filler in cement-mineral suspensions when developing self-compacting concrete mixtures.

\section{Methods and Approaches}

To prepare suspensions, Portland cement CEM I 32.5R (C) by Mordovtsement PJSC (GOST 31108) was used. The mineral part included a carbonate filler from KM100 microcalcite (MKM) by Polipark LLC with the dosage of $0 \div 300 \%$ of Portland cement weight $(0 \div 75 \%$ of solid phase weight) with the variability pitch of $100 \%$. Melflux $5581 \mathrm{~F}$ (SP) polycarboxylate superplasticizer by BASF Construction Solutions (Trostberg, Germany) was used as a plasticizer.

The study was carried out with the fixed water-solid ratio $\mathrm{W} / \mathrm{S}=0.15$ with the varying factors being:

- ratio $\mathrm{MKM} / \mathrm{C}, x_{1}=0 \div 3.0$ relative units;

- ratio $\mathrm{SP} /(\mathrm{C}+\mathrm{MKM}), x_{2}=0 \div 1.5 \%$.

\section{Results and Discussion}

The study results were used to develop an experimentally statistical (ES) model describing the changes in the flow diameter of cement-carbonate suspensions (Portland cement + microcalcite $)\left[D_{f}^{\mathrm{HC}}, \mathrm{mm}\right]$ from the Hegermann cone from the content of the varying factors $x_{1}$ and $x_{2}$ :

$$
\begin{gathered}
D_{f}^{\mathrm{HC}}=288.9+52.9 \cdot x_{1}+64.8 \cdot x_{2}+19.8 \cdot x_{1} \cdot x_{2}-51.33 \cdot x_{1}^{2} \\
-89.3 \cdot x_{2}^{2}+37.97 \cdot x_{1}^{3}+32.34 \cdot x_{2}^{3}-59.06 \cdot x_{1} \cdot x_{2}^{2} \\
-15.19 \cdot x_{1}^{2} \cdot x_{2}+31.64 \cdot x_{1}^{2} \cdot x_{2}^{2} .
\end{gathered}
$$

Using the polynomial (1), isolines have been built, which reflect the changes in the flow diameter of cement-carbonate suspensions from the Hegermann cone depending on the content of microcalcite and Melflux 5581 F superplasticizer (Fig. 1). It has been 
found that for the constant water/solid ratio of $\mathrm{W} / \mathrm{S}=0.15$ relative units, an increase in the dosage of the superplasticizer and the mineral filler (microcalcite) causes a significant increase in the flow diameter of the cement-mineral suspension.

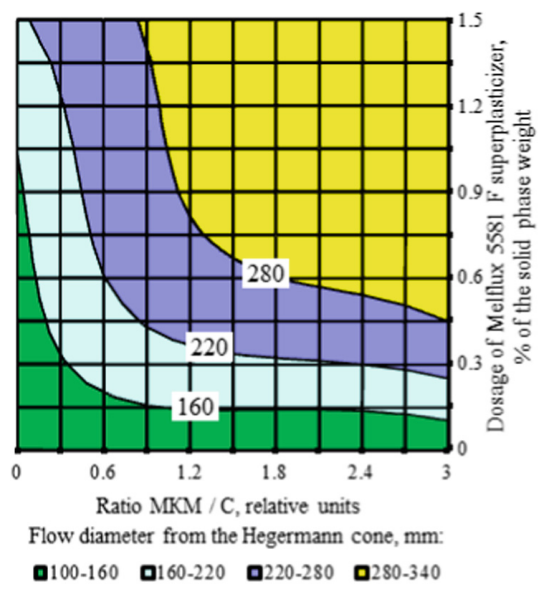

Fig. 1. Changes in the flow diameter of cement-carbonate suspensions from the Hegermann cone depending on the superplasticizer dosage and microcalcite filling degree

Analysis on Fig. 1 shows that cement suspensions without microcalciteat the specified water content W/S $=0.15$ begin to flow under the action of gravity and the value of the Hegermann cone flow diameter $D_{f}^{\mathrm{HC}}=100 \div 135 \mathrm{~mm}$ with superplasticizer quantities exceeding $0.1 \div 0.5 \%$ the mass of the solid phase. However, even an increase in the superplasticizer content to $1.0 \div 1.5 \%$ does not allow achieving self-compacting of suspensions $\left(D_{f}^{\mathrm{HC}}=160 \div 210<280 \mathrm{~mm}\right)$.

It was determined (Fig. 1) that the level of rheo-technological indices specified for self-compacting suspensions $\left(\mathrm{D}_{f}^{\mathrm{HC}} \geq 280 \mathrm{~mm}\right)$ is achieved at the microcalcite content $x_{1}=0.82 \div 3.0$ relative units $(82 \div 300 \%$ of the Portland cement mass or $45 \div 75 \%$ of the solid phase mass $(\mathrm{C}+\mathrm{MKM}))$ and the quantity of Melflux $5581 \mathrm{~F}$ superplasticizer $x_{2}=0.45 \div 1.5 \%$ of the solid phase mass, wherein when decreasing the indicator $x_{1}$, an increase in the indicator $x_{2}$ in the specified ranges $\left(\left(x_{1}=3.0\right.\right.$ relative units; $\left.x_{2}=0.45 \%\right) \rightarrow\left(x_{1}=0.82\right.$ relative units; $\left.\left.x_{2}=1.5 \%\right)\right)$ is required.

\section{Conclusions}

The analysis of research results found the optimal levels of the varying factors that allow reaching the self-compacting of suspensions for the flow diameter from the Hegermann cone above $280 \mathrm{~mm}$ and the water/solid ratio of 0.15 relative units: the dosage of Melflux $5581 \mathrm{~F}$ superplasticizer is $0.5 \div 1.0 \%$ of the solid phase weight; the filling degree of suspension with microcalcite is at least $105 \%$ of the Portland cement weight. 
Acknowledgements. The reported study was funded by RFBR according to the research project № 18-29-12036.

\section{References}

Collepardi M (2006) The New Concrete. Grafiche Tintoretto, Villorba

Kalashnikov VI, Moskvin RN, Belyakova EA, Belyakova VS, Petukhov AV (2014) Highdispersity fillers for powder-activated concretes of new generation. Syst Methods Technol 2 (22):113-118

Nawy EG (2001) Fundamentals of High-Performance Concrete. Wiley, New York

Nizina TA, Balykov AS (2016) Experimental-statistical models of properties of modified fiberreinforced fine-grained concretes. Mag Civil Eng 2:13-25. https://doi.org/10.5862/MCE.62.2

Nizina TA, Ponomarev AN, Balykov AS, Pankin NA (2017) Fine-grained fibre concretes modified by complexed nanoadditives. Int J Nanotechnol 14:665-679. https://doi.org/10. 1504/IJNT.2017.083441

Okamura H, Ouchi M (2003) Self-compacting concrete. J Adv Concr Technol 1:5-15

Sivakumar N, Muthukumar S, Sivakumar V, Gowtham D, Muthuraj D (2014) Experimental studies on high strength concrete by using recycled coarse aggregate. Res Inventy: Int J Eng Sci 4:27-36

Tran NT, Kim DJ (2017) Synergistic response of blending fibers in ultra-high-performance concrete under high rate tensile loads. Cement Concr Compos 78:132-145

Open Access This chapter is licensed under the terms of the Creative Commons Attribution 4.0 International License (http://creativecommons.org/licenses/by/4.0/), which permits use, sharing, adaptation, distribution and reproduction in any medium or format, as long as you give appropriate credit to the original author(s) and the source, provide a link to the Creative Commons license and indicate if changes were made.

The images or other third party material in this chapter are included in the chapter's Creative Commons license, unless indicated otherwise in a credit line to the material. If material is not included in the chapter's Creative Commons license and your intended use is not permitted by statutory regulation or exceeds the permitted use, you will need to obtain permission directly from the copyright holder.

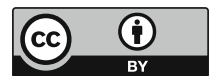

